\title{
Deleting both PHLPP1 and CANP1 rescues impairments in long-term potentiation and learning in both single knockout mice
}

\author{
Yan Liu, ${ }^{1}$ Jiandong Sun, ${ }^{2}$ Yubin Wang, ${ }^{1}$ Dulce Lopez, ${ }^{1}$ Jennifer Tran, ${ }^{1,2}$ Xiaoning Bi, ${ }^{2}$ \\ and Michel Baudry ${ }^{1}$ \\ ${ }^{1}$ Graduate College of Biomedical Sciences; ${ }^{2}$ College of Osteopathic Medicine of the Pacific, Western University of Health Sciences, \\ Pomona, California 91766, USA
}

\begin{abstract}
Calpain-1 (CANPI) has been shown to play a critical role in synaptic plasticity and learning and memory, as its deletion in mice results in impairment in theta-burst stimulation- (TBS) induced LTP and various forms of learning and memory. Likewise, PHLPP1 (aka SCOP) has also been found to participate in learning and memory, as PHLPP1 overexpression impairs hippocampus-dependent learning. We previously showed that TBS-induced LTP was associated with calpain-1 mediated truncation of PHLPPI.To better understand the roles of these 2 genes in synaptic plasticity and learning and memory, we generated a double knockout (DKO) mouse by crossing the parent strains. Surprisingly, DKO mice exhibit normal TBS-induced LTP, and the learning impairments in fear conditioning and novel object or novel location recognition were absent in the DKO mice. Moreover, TBS-induced ERK activation in field CAl of hippocampal slices, which is impaired in both single deletion mice, was restored in the DKO mice. These results further strengthen the roles of both CANP1 and PHLPP1 in synaptic plasticity and learning and memory, and illustrate the complexities of the interactions between multiple pathways participating in synaptic plasticity.
\end{abstract}

While tremendous progress has been made regarding our understanding of the molecular/cellular mechanisms underlying learning and memory, many questions regarding the roles of various signaling pathways activated during learning remain unanswered (Baudry et al. 2015; Mehta 2015; Tonegawa et al. 2015; Smolen et al. 2016). In particular, while the calcium-dependent protease, calpain, has been proposed to participate in synaptic plasticity and learning and memory many years ago (Lynch and Baudry 1984), its precise contributions are still not clearly understood. This is in part due to the existence in the brain of two major calpain isoforms, calpain-1 (aka, $\mu$-calpain) and calpain-2 (aka, m-calpain), and the lack of tools to study their respective functions in synaptic plasticity. Our previous studies have shown that long-term potentiation (LTP) elicited by theta-burst stimulation (TBS), as well as learning of hippocampus-dependent tasks were impaired in calpain-1 knockout (CANP1-/-) mice (Zhu et al. 2015; Liu et al. 2016). We also found that these impairments were related to the lack of calpain-1-mediated truncation of the $\mathrm{PH}$ domain and Leucine-rich repeat Protein Phosphatase 1 (PHLPP1, aka suprachiasmatic nucleus oscillatory protein (SCOP)) and the resulting stimulation of the extracellular signal-regulated kinase (ERK), which plays an important role in LTP induction and in learning and memory (Wang et al. 2014). On the other hand, calpain-2 activation was found to limit the extent of potentiation in hippocampal slices and learning of hippocampus-dependent tasks (Liu et al. 2016). It has previously been reported that PHLPP1 overexpression impairs learning and memory (Shimizu et al. 2007), suggesting that PHLPP1 could also participate in synaptic plasticity (Shimizu et al. 2010).

To further evaluate the role of the calpain-1-mediated truncation of PHLPP1 in synaptic plasticity, we generated CANP1-

\section{Corresponding author: mbaudry@westernu.edu}

Article is online at http://www.learnmem.org/cgi/doi/10.1101/Im.042721.116. and PHLPP1-double-knockout mice (DKO) and analyzed the properties of LTP in hippocampal slices from wild-type (WT), CANP1 - / - , PHLPP1 - / - , and DKO mice. TBS-induced actin polymerization within dendritic spines has also been shown to be an essential step in LTP consolidation, and we also determined whether it was occurring in CANP1 $-/-$, PHLPP1 $-/-$ and DKO mice. Finally, we analyzed the effects of the combined deletion of CANP1 and PHLPP1 as opposed to each single deletion on longterm memory in a fear-conditioning paradigm and in novel object recognition. Our results indicate that deletion of PHLPP1 impaired LTP and some forms of learning but its deletion in CANP1 - / - mice reestablished TBS-induced LTP and the resulting actin polymerization, and learning of hippocampal tasks, an effect probably due to the rescue of TBS-induced ERK activation.

\section{Results}

Combined deletion of CANPI and PHLPP1 rescues impairment in TBS-induced LTP in single deletion mice

We previously reported that TBS-induced LTP induction was impaired in hippocampal slices from CANP1-/- mice (Zhu et al. 2015), and that calpain-1-mediated PHLPP1 truncation played an important role in LTP induction and consolidation (Wang et al. 2014). As previously reported, synaptic responses returned to basal levels $30 \mathrm{~min}$ after TBS in hippocampal slices from CANP1 $-/-$ mice (EPSP slope values at $40 \mathrm{~min}$ : $108 \pm 3 \%$ of

(C) 2016 Liu et al. This article is distributed exclusively by Cold Spring Harbor Laboratory Press for the first 12 months after the full-issue publication date (see http://learnmem.cshlp.org/site/misc/terms.xhtml). After 12 months, it is available under a Creative Commons License (Attribution-NonCommercial 4.0 International), as described at http://creativecommons.org/licenses/ by-nc/4.0\%. 
A

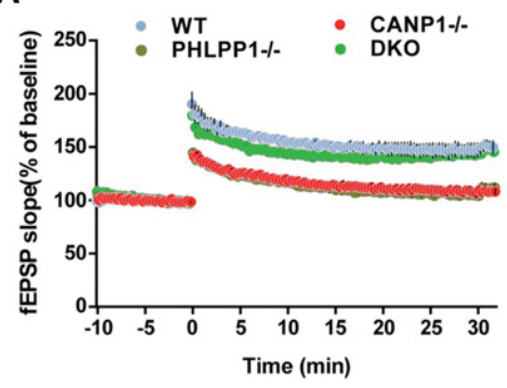

B

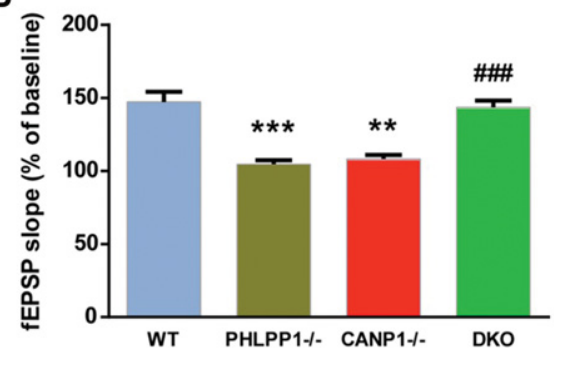

Figure 1. Combined deletion of CANP1 and PHLPP1 rescues impairment in TBS-induced LTP in single deletion mice. (A) TBS-induced LTP in hippocampal slices from WT, PHLPP1 $-/-$, CANP1 $-/-$ and DKO mice. fEPSP slopes were calculated as percent of fEPSP slopes averaged over the 10-min baseline period. (B) Means \pm SEM of fEPSPs measured $30 \mathrm{~min}$ after TBS in the different groups. $\mathrm{N}=3-6$ slices from 3-5 mice, $\left(^{* *}\right) P<0.01$ (***) $P<0.001$, when compared with WT slices, and (\#\#\#) $P<0.001$, when compared with CANP1 - / - mice, two-way ANOVA with Newman-Keuls post-test.

baseline response) (Fig. 1A). Surprisingly, the same stimulation protocol performed in hippocampal slices from PHLPP1 - / $\mathrm{KO}$ mice also failed to induce LTP (EPSP slope values at $40 \mathrm{~min}$ : $111 \pm 4 \%$ of baseline response) (Fig. 1A). However, the same stimulation protocol performed in hippocampal slices from DKO mice elicited stable LTP (EPSP slope values at $30 \mathrm{~min}: 146 \pm 6 \%$ of baseline response), which was similar to that found in hippocampal slices from WT mice (EPSP slope values at $30 \mathrm{~min}$ : $150 \pm 7 \%$ of baseline response).
Combined deletion of CANP1 and PHLPP1 rescues impaired TBS-induced actin polymerization in single deletion mice

Actin polymerization has been shown to be a necessary event for TBS-induced LTP (Lin et al. 2005; Zhu et al. 2015), and for long-term memory formation (Huang et al. 2013). Using the phalloidinlabeling assay to visualize fibrous actin (F-actin), we observed an increase in actin polymerization $25 \mathrm{~min}$ after TBS in stratum radiatum of WT mice (Fig. 2). In both CANP1 - / - and PHLPP1-/mice, TBS did not increase actin polymerization (Fig. 2), a result consistent with the requirement for actin polymerization in LTP stabilization (Fig. 1A). In contrast, TBS did elicit an increase in actin polymerization in hippocampal slices from DKO mice, an effect consistent with the rescue of TBS-induced LTP (Fig. 2).

\section{PHLPP1 deletion rescues context-dependent fear} conditioning impairment in CANP1 - / - mice

In agreement with our previously results (Zhu et al. 2015), CANP1 - / - mice exhibited deficits in fear conditioning when trained with one tone-foot-shock pairing (Fig. 3). With the same

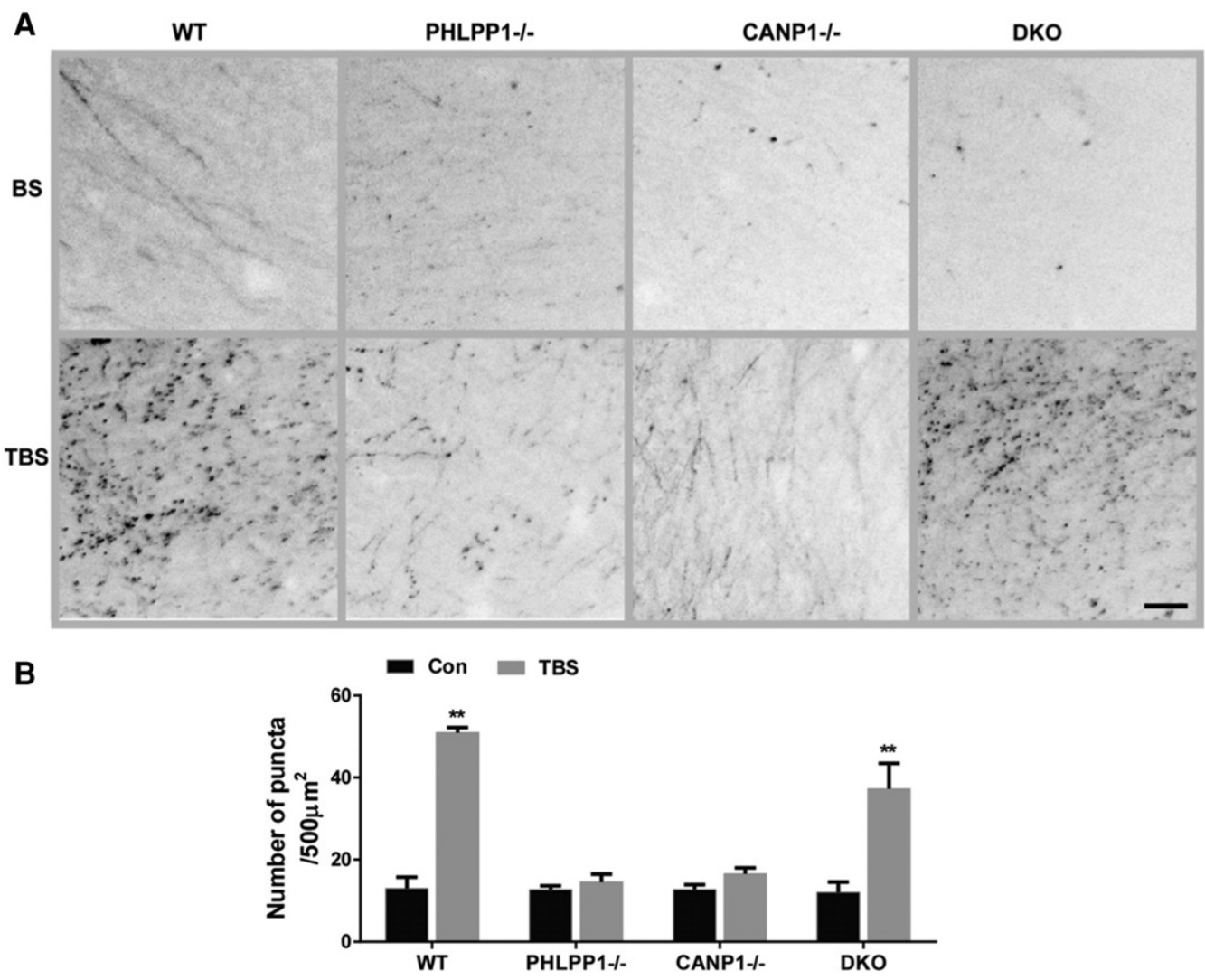

Figure 2. Combined deletion of CANP1 and PHLPP1 rescues impairment in TBS-induced actin polymerization in single deletion mice. ( $A$ ) Representative images of phalloidin staining in slices from WT, PHLPP1 - / - CANP1 - / -, and DKO mice after 10 min of baseline stimulation (BS) or TBS. Scale bar $=20 \mu \mathrm{m}$. (B) Quantitative analysis of F-actin staining. Data are means \pm SEM. (**) $P<0.01$, when compared with baseline (BS). Two-way ANOVA followed by Bonferroni test. $N=4-6$ slices from 3-5 mice for each group. 
A

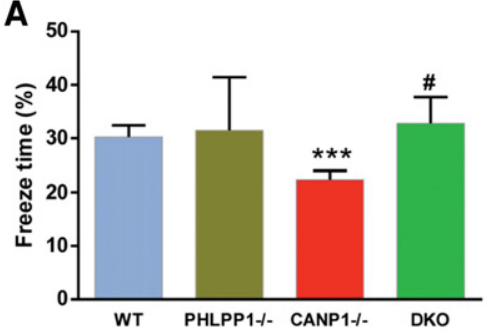

B

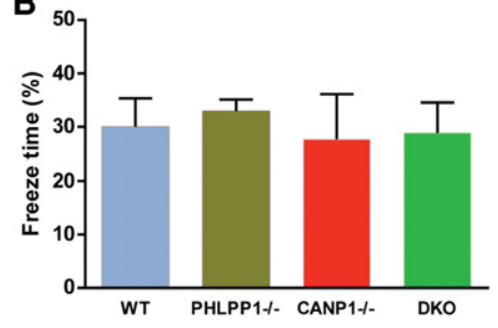

Figure 3. PHLPP1 deletion rescues impairment in context-dependent fear conditioning in CANP1 - / - mice. (A) Percent freezing for different experimental groups in context-dependent fear conditioning (means \pm SEM. of 6-9 mice; $\left(^{* * *}\right) P<0.001$, when compared with WT controls, (\#) $P<0.05$, when compared with CANP1 - / - mice; two-way ANOVA with Newman-Keuls post hoc analysis). (B) Percent freezing for different experimental groups in tone-dependent fear conditioning (means \pm SEM. of 6-9 mice).

training protocol, PHLPP1 - / - did not exhibit deficit as compared with WT mice. On the other hand, DKO mice exhibited normal learning, when compared with WT mice. Thus PHLPP1 deletion rescues the impairment in context-dependent fear conditioning learning in CANP1-/- mice. There was no significant difference between any groups when we tested the mice in tone-induced fear conditioning (Fig. 3B).

\section{Combined deletion of CANP1 and PHLPP1 rescues spatial learning and memory deficits in single deletion mice}

To further confirm the function of calpain-1-mediated truncation of PHLPP1 in spatial learning and memory, we tested the various groups of mice in both short-term (1-h retention) and long-term (24-h retention) object location memory (OLM) and object recognition memory (ORM). Single deletion mice displayed significant deficits in both short-term and long-term learning in both OLM test and ORM test, when compared with WT mice (Figs. 4,5). In contrast, DKO mice exhibited normal memory, when compared with WT mice (Figs. $4,5)$.

\section{Combined deletion of CANP1 and PHLPP1 rescues TBS-induced ERK activation in single deletion \\ mice}

We previously proposed that impairment in both LTP induction and learning and memory observed in CANP1-/- mice were due to the lack of calpain-1mediated truncation of PHLPP1, resulting in decreased ERK activation (Wang et al. 2014). It was therefore of interest to determine whether TBS could elicit ERK activation in hippocampal slices from DKO mice. CA1 mini-slices were prepared from the various mouse strains and TBS was delivered to stratum radiatum of CA1. Ten minutes later, slices were collected and levels of p-ERK and ERK were analyzed by Western blots. As previously reported, TBS elicited
A

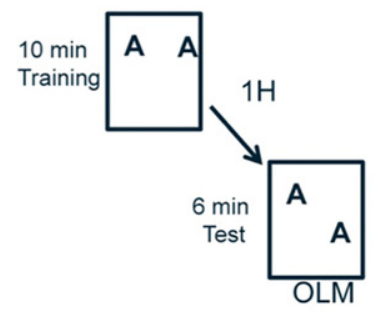

C

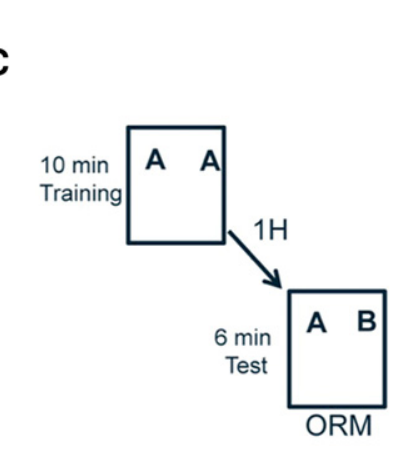

increased ERK phosphorylation in slices from WT but not CANP1 - / - mice (Fig. 6). Because PHLPP1 is a negative regulator of ERK, calpain-1-mediated-PHLPP1 truncation plays a very important role in TBS-induced LTP (Wang et al. 2014). TBS failed to induce ERK phosphorylation in PHLPP1-/- mice (Fig. 6A). However, TBS elicited ERK phosphorylation in slices from DKO mice, which was similar to that found in WT mice.

\section{Discussion}

The present results provide new information regarding the roles of calpain-1, PHLPP1, and calpain-1-mediated truncation of PHLPP1 in LTP and learning and memory. Thus, as we previously reported, calpain-1 activation is required for TBS-induced LTP formation and for certain forms of learning, including context-dependent fear conditioning and novel object location and recognition, which are known to be hippocampus-dependent (Vogel-Ciernia and Wood 2014; Ameen-Ali et al. 2015; Izquierdo et al. 2016). On the other hand, calpain-1 activation does not appear to be required for tone-dependent fear conditioning, which is generally considered to be amygdala-dependent (Maren et al. 2001). In addition, calpain- 1 activation is also required for TBS-induced actin polymerization and ERK activation, which is

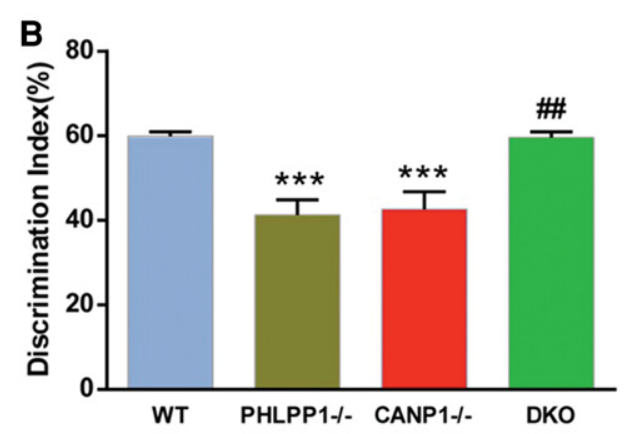

D

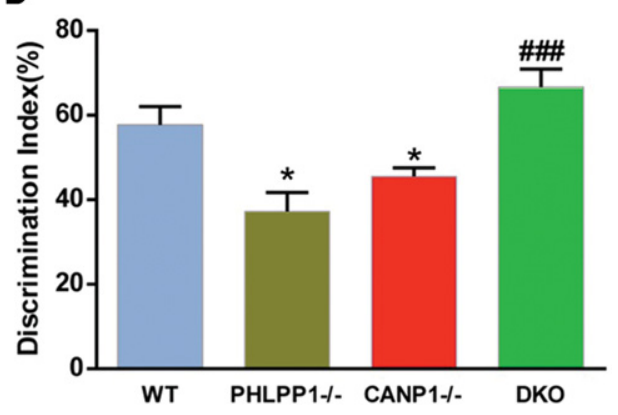

Figure 4. Combined deletion of CANP1 and PHLPP1 rescues short-term memory impairment in single deletion mice. $(A)$ Mice received $10 \mathrm{~min}$ of training in an environment with two identical objects and received a retention test $1 \mathrm{~h}$ later in which one object was moved to a new location (OLM). (B) CANP1 - / - and PHLPP1 - / - KO mice exhibited a significant deficit when tested $1 \mathrm{~h}$ after training, but DKO mice were not significantly different from WT mice $\left(\mathrm{N}=6-8\right.$ mice $\left({ }^{* * *}\right)$ $P<0.001$, when compared with WT, (\#\#) $P<0.01$, when compared with CANP1 - / - mice). (C) Mice received $10 \mathrm{~min}$ of training in an environment with two identical objects and received a retention test $1 \mathrm{~h}$ later in which one object was replaced with a novel one (ORM). (D) CANP1 - / - and PHLPP1 $-/-$ mice exhibited a significant deficit $1 \mathrm{~h}$ after training, but DKO mice were not significantly different from WT mice $\left(N=6-8\right.$ mice $\left(^{*}\right) P<0.05$, when compared with WT, (\#\#\#) $P<0.001$, when compared with CANP1 - / - mice). 
A

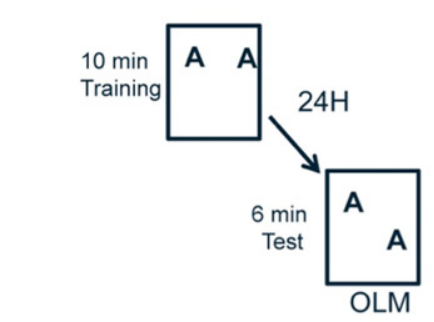

C

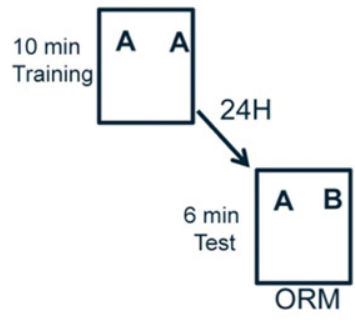

B

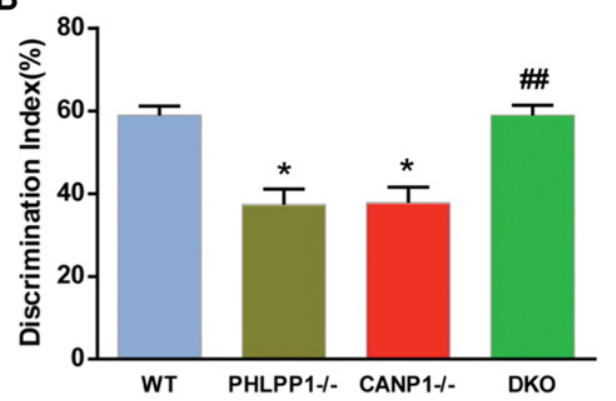

D

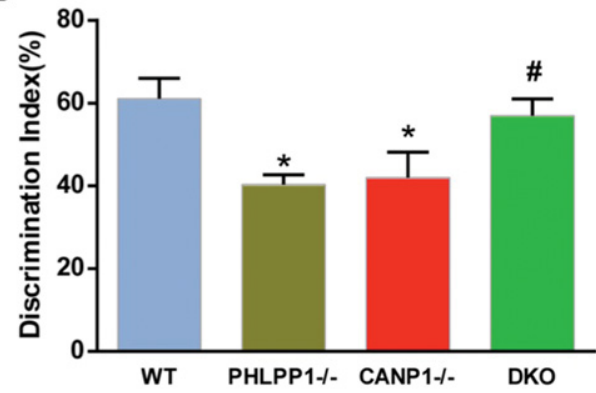

Figure 5. Combined deletion of CANP1 and PHLPP1 rescues long-term memory impairment in single deletion mice. (A) Mice received 10 min of training in an environment with two identical objects and received a retention test $24 \mathrm{~h}$ later in which one object was moved to a new location (OLM). (B) CANP1 - / - and PHLPP1 - / - mice exhibited a significant deficit $24 \mathrm{~h}$ after training but DKO were not significantly different from WT mice $\left(N=6-8\right.$ mice $\left(^{*}\right) P<0.05$, when compared with WT, (\#\#) $P<0.01$, when compared with CANP1 - / - mice). (C) Mice received 10 min of training in an environment with two identical objects and received a retention test $24 \mathrm{~h}$ later in which one object was replaced with a novel one (ORM). (D) CANP1 - / - and PHLPP1 - / - mice exhibited a significant deficit $24 \mathrm{~h}$ after training and DKO were not significantly different from WT mice $\left(N=6-8\right.$ mice $\left(^{*}\right)$ $P<0.05$, when compared with WT, (\#) $P<0.05$, when compared with CANP1 - / - mice).

consistent with the idea that actin polymerization is downstream from calpain-1 activation, while ERK activation could be due to calpain-1-mediated PHLPP1 truncation and inactivation (Wang et al. 2014).

Results with PHLPP1 - / - mice are somewhat more complicated to interpret. Previous studies had indicated that PHLPP1 was truncated during learning, while its overexpression impaired learning, which was interpreted in the context of impairment of ERK activation under this condition (Shimizu et al. 2007; Wang et al. 2014; Baudry and Bi 2016). It was therefore predicted that PHLPP1 deletion would facilitate LTP induction and learning and memory. Our results indicate that PHLPP1 deletion impaired TBS-induced LTP, had no effect on context- or tone-dependent fear conditioning, but impaired learning of novel object location or recognition. It also impaired TBS-induced actin polymerization and ERK activation. The most parsimonious explanation would be that too little or too much of PHLPP1 is deleterious for TBS-induced LTP, increased actin polymerization and certain forms of hippocampus-dependent learning. The difficulty is to account for the lack of effect of PHLPP1 deletion on contextdependent learning. In this regard, it is important to stress that this form of learning is very sensitive to the training protocol. In particular, we found that calpain-1 deletion does not impair context-dependent fear conditioning when animals are trained with three pairings of tone-foot-shocks. It is therefore possible that PHLPP1 - / - mice are able to learn the association between the context and the shock by using a synaptic plasticity mechanism different than the one engaged by TBS. In this regard, we also found that HFS-induced LTP did not engage calpain-1 and therefore calpain-1-mediated PHLPP1 truncation (Zhu et al.
2015). In addition, it has previously been shown that object location training elicits a temporally distinct transcriptional profile than contextual fear conditioning, indicating that these two forms of learning engage different molecular/ cellular processes (Poplawski et al. 2014).

The results with the combined deletion of CANP1 and PHLPP1 are quite interesting as they reveal the existence of compensatory mechanisms for both TBS-induced LTP induction and learning and memory of hippocampusdependent tasks. In our previous model, we proposed that calpain-1-mediated PHLPP1 truncation was required for ERK activation, actin polymerization, LTP formation and learning and memory. What our current results show is that in the absence of both calpain- 1 and PHLPP1, TBS can still elicit actin polymerization and ERK activation. These results indicate that under these conditions, TBS is able to trigger different signaling pathways, which can lead to actin polymerization and ERK activation. We previously discussed such pathways, which could include PKA activation (Zhu et al. 2015), although the existence of cross-talks between many signaling pathways could not eliminate the involvement of other kinases or phosphatases. In any event, the results indicate that LTP, actin polymerization, ERK activation are intricately linked to hippocampus-dependent learning, as all these forms of learning are rescued in the double knockout mice.

We previously discussed the fact that different patterns of electrical stimulation trigger different signaling pathways converging on a set of mechanisms critical for synaptic plasticity and memory formation, and that depending on the conditions, the same pattern of stimulation can activate a different signaling pathway form the one it normally activates (Zhu et al. 2015). These results underscore the existence of a significant degree of redundancy in the mechanisms of synaptic plasticity and learning and memory. Such redundancy should be taken into account for developing new strategies to treat disorders associated with learning and memory impairment.

\section{Experimental procedures}

Animal use in all experiments followed NIH guidelines and all protocols were approved by the Institution Animal Care and Use Committee of Western University of Health Sciences.

Calpain-1 knockout mice: CANP1 - / - mice on a C57Bl/6 background were obtained from a breeding colony established from breeding pairs generously provided by Dr. Chishti (Tufts University). C57Bl/6 mice were purchased from Jackson Labs and were the corresponding WT.

PHLPP1 knockout mice: PHLPP1 - / - mice on a C57/SV129 background were obtained from a breeding colony established from breeding pairs generously provided by Dr. Newton (UCSD).

Calpain-1/PHLPP1 double knockout mice: CANP1-/on the $\mathrm{C} 57 \mathrm{Bl} / 6$ background were crossed with PHLPP1-/- on the C57/SV129 background to produce CANP1-/-/ PHLPP1+/-. CANP1 - / - / PHLPP1+/- were backcrossed with 
A

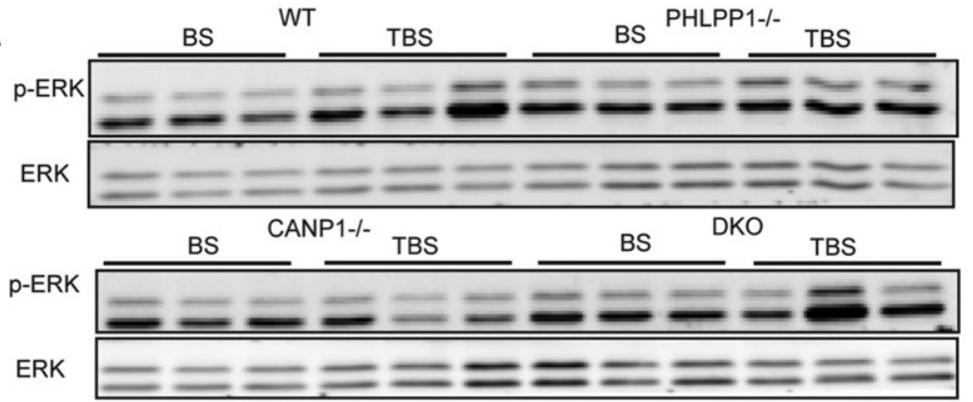

B

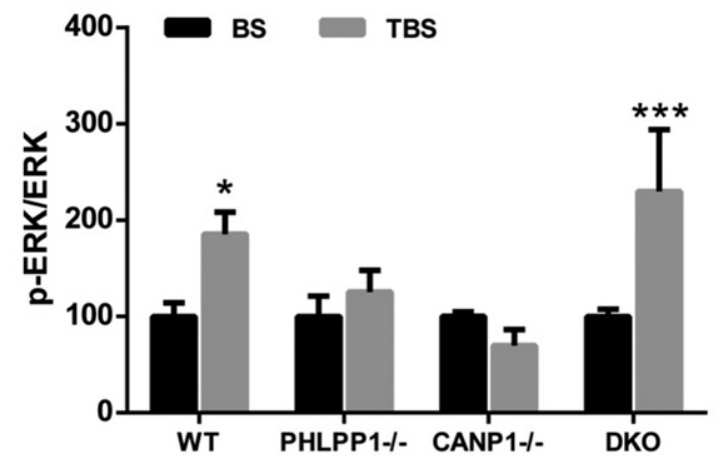

Figure 6. Combined deletion of CANP1 and PHLPP1 rescues impairment in TBS-induced ERK activation in single deletion mice. (A) Hippocampal CA1 mini slices were collected 10 min after TBS (TBS group) or low frequency stimulation (baseline stimulation, BS). TBS induced ERK activation in WT and DKO mice, but not in CANP1 - / - or PHLPP1 - - mice. (B) Quantification data for p-ERK levels. $N=4$. $\left({ }^{*}\right) P<0.05$, when compared with baseline stimulation $(B S),\left({ }^{* *}\right) P<0.001$, when compared with baseline stimulation (BS) (one-way ANOVA followed by Bonferroni test). es at $100 \mathrm{~Hz}$ delivered at $5 \mathrm{~Hz}$ ). For LTP experiment, stimulation intensity was adjusted to elicit $40 \%$ of the maximal EPSP slope, except when otherwise indicated. Responses during baseline and after tetanus stimulation were recorded every $20 \mathrm{sec}$. Data were collected and digitized by Clampex, and the slope of fEPSP was analyzed. LTP level was normalized to the average slope of responses recorded during the 10-min baseline, and responses were recorded for at least 30 min after LTP induction.

\section{Western blotting}

To analyze activity-dependent regulation of different proteins, CA1 mini-slices were obtained by dissecting out the CA1 region before transferring them to the recording chamber. After $2 \mathrm{~h}$ incubation in aCSF, slices were subjected to different stimulations. Ten minutes after stimulation, slices were collected for Western blotting assay. Slices were lysed and protein concentrations were measured using the BCA protein assay kit (Thermo Scientific). Equal amounts of proteins were processed for SDS-PAGE and Western blot. The primary antibodies used were phospho-ERK (1:3000, Cell Signaling Technology), ERK (1:3000, Cell Signaling Technology).
CANP1 $-/-$ to produce CANP1 - / - / PHLPP1 $1-$ - These mice were then intercrossed to generate CANP1 - / - / PHLPP1 - / mice (DKO).

\section{Acute hippocampal slice preparation}

Hippocampal slice preparation and electrophysiological recording were performed as previously reported (Sun et al. 2015). Adult male mice (3- to 4-mo-old) were anesthetized with halothane and decapitated. Brains were quickly removed and transferred to oxygenated, ice-cold cutting medium (in $\mathrm{mM}$ ) as follows: $124 \mathrm{NaCl}, 26 \mathrm{NaHCO}_{3}, 10$ glucose, $3 \mathrm{KCl}, 1.25 \mathrm{KH}_{2} \mathrm{PO}_{4}$, $5 \mathrm{MgSO}_{4}$, and $3.4 \mathrm{CaCl}_{2}$. Hippocampal transversal slices (350 $\mu \mathrm{m}$ thick) were prepared using a McIIwain-type tissue chopper and transferred to an interface recording chamber and exposed to a warm, humidified atmosphere of $95 \% \mathrm{O}_{2} / 5 \% \mathrm{CO}_{2}$ and continuously perfused with oxygenated and preheated $\left(33 \pm 0.5^{\circ} \mathrm{C}\right)$ aCSF (in $\mathrm{mM}$ ) as follows: $110 \mathrm{NaCl}, 5 \mathrm{KCl}, 2.5 \mathrm{CaCl}_{2}, 1.5$ $\mathrm{MgSO}_{4}, 1.24 \mathrm{KH}_{2} \mathrm{PO}_{4}, 10 \mathrm{D}$-glucose, 27.4 $\mathrm{NaHCO}_{3}$, at a speed of $1.4 \mathrm{~mL} / \mathrm{min}$.

\section{Electrophysiology}

Electrophysiology recording were performed as previously reported (Zhu et al. 2015). After $2 \mathrm{~h}$ of incubation at $33.0 \pm 0.5^{\circ} \mathrm{C}$ in recording chamber, a single glass pipette filled with $2 \mathrm{M} \mathrm{NaCl}$ was used to record field EPSPs (fEPSPs) elicited by stimulation of the Schaffer collateral pathway with twisted nichrome wires (single bare wire diameter, $50 \mu \mathrm{m}$ ) placed in CA1 stratum radiatum. Responses were recorded through a differential amplifier (DAM 50, World Precision Instruments) with a $10 \mathrm{kHz}$ low-pass and $0.1 \mathrm{~Hz}$ high-pass filter. LTP was induced by TBS (10 bursts of 4 puls-

\section{In situ phalloidin labeling}

Methods for analyzing actin polymerization were slightly modified from those described previously (Kramar et al. 2006). Rhodamine-phalloidin $(6 \mu \mathrm{M})$ was applied topically from a micropipette every $5 \mathrm{~min}$ for $20 \mathrm{~min}$ in slices that received lowfrequency stimulation after the delivery of TBS. Slices were then collected and fixed in 4\% PFA for $1 \mathrm{~h}$, cryoprotected in 30\% sucrose for $1 \mathrm{~h}$ at $4^{\circ} \mathrm{C}$, and sectioned on a freezing microtome at $20 \mu \mathrm{m}$. Labeling was examined using a Nikon C1confocal laserscanning microscope $(60 \times)$. Identification and measurement of labeled spines were performed on a $500 \mu \mathrm{m}^{2}$ sampling area within the zone of physiological recording as described previously (Zhu et al. 2015). Spine numbers in each image were analyzed with the ImageJ software. The threshold was set to count the puncta numbers. Particles with sizes from 20 to 100 pixels were counted in each field.

\section{Behavioral test}

\section{Object location and novel object recognition tasks}

Object location and object recognition were performed as previously described (Vogel-Ciernia et al. 2013; Zhu et al. 2015). Prior to training, mice habituated to the experimental apparatus for 5 min in the absence of objects. During habituation, animals were allowed to explore an empty arena. Twenty-four hours after habituation, animals were exposed to the familiar arena with two identical objects added and allowed to explore for $10 \mathrm{~min}$. During the retention test $(24 \mathrm{~h}$ for long-term memory or $60 \mathrm{~min}$ for shortterm memory), mice were allowed to explore the experimental apparatus for $6 \mathrm{~min}$. Exploration was scored when a mouse's head was oriented toward the object within a distance of $1 \mathrm{~cm}$ or 
when the nose was touching the object. The relative exploration time ( $t$ ) was recorded and expressed as a discrimination index $\left(\mathrm{DI}=\left(t_{\text {novel }}-t_{\text {familiar }}\right) /\left(t_{\text {novel }}+t_{\text {familiar }}\right) \times 100 \%\right)$. Mean exploration times were then calculated and the discrimination indexes between treatment groups compared. Mice that explored both objects for $<3 \mathrm{sec}$ in total during either training or testing were removed from further analysis. Mice that demonstrated an object preference during training (DI $> \pm 20$ ) were also removed (Vogel-Ciernia et al. 2013).

\section{Fear conditioning}

Mice were housed individually with normal 12/12 h daylight cycle. They were handled daily for $5 \mathrm{~d}$ before training. On training day, mice were placed in the fear conditioning chamber (H10$11 \mathrm{M}-\mathrm{TC}$, Coulbourn Instruments) located in the center of a sound-attenuating cubicle (Coulbourn Instruments). The conditioning chamber was cleaned with $10 \%$ ethanol to provide a background odor. A ventilation fan provided a background noise at $-55 \mathrm{~dB}$. After a 2-min exploration period, one tone-foot-shock pairings separated by 1-min intervals were delivered. The $85-\mathrm{dB}$ $2-\mathrm{kHz}$ tone lasted for $30 \mathrm{sec}$, and the foot shock was $0.75 \mathrm{~mA}$ and lasted for $2 \mathrm{sec}$. Foot shock coterminated with the tone. Mice remained in the training chamber for another $30 \mathrm{sec}$ before being returned to their home cages. Context test was performed 1 $\mathrm{d}$ after training. Mice were placed back into the original conditioning chamber, and their behaviors were recorded for $5 \mathrm{~min}$. On day 3 , animals were subjected to cue/tone test. The same conditioning chamber was modified by changing its metal grid floor to a plastic sheet, white metal walls to plastic walls gridded with red tapes, and odor from ethanol to acetic acid. The ventilation fan was turned off to reduce background noise, and the ceiling light was changed from yellow to white. Mice were placed in the altered chamber for $5 \mathrm{~min}$ to measure freezing level in the altered context; and after this 5 -min period, a tone $(85 \mathrm{~dB}, 2 \mathrm{kHz})$ was delivered for $1 \mathrm{~min}$ to measure freezing to tone. Mice behavior was recorded with the Freezeframe software and analyzed with Freezeview software (Coulbourn Instruments). Motionless bouts lasting $1 \mathrm{sec}$ were considered as freezing. The percentage of time animal froze was calculated, and the group means with SEM and accumulative distribution of percentage freeze were analyzed.

\section{Statistical analyses}

Data are presented as means \pm SEM. For experiments where only two groups were compared, two-tail $t$-test was used for determining statistical significance. When more than two groups were compared, we used one-way ANOVA or two-way ANOVA followed by Bonferroni test to determine statistical significance. $P$ values $<0.05$ were considered statistically significant.

\section{Acknowledgments}

This work was supported by grant P01NS045260-01 from NINDS (PI: Dr. C.M. Gall), grant R01NS057128 from NINDS to M.B., and grant R15MH101703 from NIMH to X.B. X.B. is also supported by funds from the Daljit and Elaine Sarkaria Chair. The authors are very grateful to Dr. A. Chishti (Tufts University) and Dr. Alexandra Newton (UCSD) for providing us breeding pairs of CANP1 $-/-$ and PHLPP1 - / - mice, respectively, to generate the mice used in this study.
Author contributions: Y.L. performed the electrophysiological and the behavioral experiments analyzed the data and wrote the manuscript; J.S. performed the immunohistochemical experiments, Y.W., D.L., and J.T. generated the DKO mice, X.B. designed some of the experiments, and wrote the manuscript; M.B. designed the experiments, directed the studies, and wrote the manuscript.

\section{References}

Ameen-Ali KE, Easton A, Eacott MJ. 2015. Moving beyond standard procedures to assess spontaneous recognition memory. Neurosci Biobehav Rev 53: 37-51.

Baudry M, Bi X. 2016. Calpain-1 and calpain-2: the yin and yang of synaptic plasticity and neurodegeneration. Trends Neurosci 39: $235-245$.

Baudry M, Zhu G, Liu Y, Wang Y, Briz V, Bi X. 2015. Multiple cellular cascades participate in long-term potentiation and in hippocampus-dependent learning. Brain Res 1621: 73-81.

Huang W, Zhu PJ, Zhang S, Zhou H, Stoica L, Galiano M, Krnjević K, Roman G, Costa-Mattioli M. 2013. mTORC2 controls actin polymerization required for consolidation of long-term memory. Nat Neurosci 16: 441-448.

Izquierdo I, Furini CR, Myskiw JC. 2016. Fear Memory. Physiol Rev 96: $695-750$.

Kramar EA, Lin B, Rex CS, Gall CM, Lynch G. 2006. Integrin-driven actin polymerization consolidates long-term potentiation. Proc Nat Acad Sci 103: $5579-5584$.

Lin B, Kramar EA, Bi XN, Brucher FA, Gall CM, Lynch G. 2005. Theta stimulation polymerizes actin in dendritic spines of hippocampus. I Neurosci 25: 2062-2069.

Liu Y, Wang Y, Zhu G, Sun J, Bi X, Baudry M. 2016. A calpain-2 selective inhibitor enhances learning \& memory by prolonging ERK activation. Neuropharmacology 105: 471-477.

Lynch G, Baudry M. 1984. The biochemistry of memory: a new and specific hypothesis. Science 224: $1057-1063$.

Maren S, Yap SA, Goosens KA. 2001. The amygdala is essential for the development of neuronal plasticity in the medial geniculate nucleus during auditory fear conditioning in rats. J Neurosci 21: RC135.

Mehta MR. 2015. From synaptic plasticity to spatial maps and sequence learning. Hippocampus 25: 756-762.

Poplawski SG, Schoch H, Wimmer ME, Hawk JD, Walsh JL, Giese KP, Abel T. 2014. Object-location training elicits an overlapping but temporally distinct transcriptional profile from contextual fear conditioning. Neurobiol Learn Mem 116: 90-95.

Shimizu K, Phan T, Mansuy IM, Storm DR. 2007. Proteolytic degradation of SCOP in the hippocampus contributes to activation of MAP kinase and memory. Cell 128: 1219-1229.

Shimizu K, Mackenzie SM, Storm DR. 2010. SCOP/PHLPP and its functional role in the brain. Mol Biosyst 6: 38-43.

Smolen P, Zhang Y, Byrne JH. 2016. The right time to learn: mechanisms and optimization of spaced learning. Nat Rev Neurosci 17: 77-88.

Sun J, Zhu G, Liu Y, Standley S, Ji A, Tunuguntla R, Wang Y, Claus C, Luo Y, Baudry M, et al. 2015. UBE3A regulates synaptic plasticity and learning and memory by controlling SK2 channel endocytosis. Cell Rep 12: $449-461$.

Tonegawa S, Liu X, Ramirez S, Redondo R. 2015. Memory engram cells have come of age. Neuron 87: 918-931.

Vogel-Ciernia A, Wood MA. 2014. Examining object location and object recognition memory in mice. Curr Protoc Neurosci 69: 8.31.1-8.31.17.

Vogel-Ciernia A, Matheos DP, Barrett RM, Wood MA. 2013. The neuron-specific chromatin regulatory subunit BAF53b is necessary for epigenetic regulation of synaptic plasticity and memory. Neuropsychopharmacology 38: S325-S326.

Wang Y, Zhu G, Briz V, Hsu YT, Bi X, Baudry M. 2014. A molecular brake controls the magnitude of long-term potentiation. Nat Commun 5: 3051.

Zhu G, Liu Y, Wang Y, Bi X, Baudry M. 2015. Different patterns of electrical activity lead to long-term potentiation by activating different intracellular pathways. J Neurosci 35: 621-633.

Received April 19, 2016; accepted in revised form May 18, 2016. 


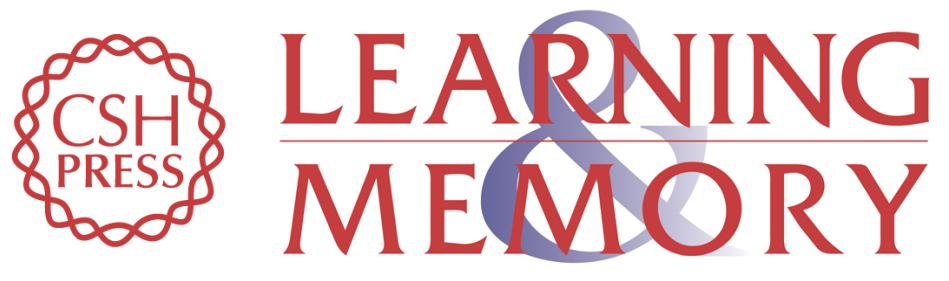

\section{Deleting both PHLPP1 and CANP1 rescues impairments in long-term potentiation and learning in both single knockout mice}

Yan Liu, Jiandong Sun, Yubin Wang, et al.

Learn. Mem. 2016, 23:

Access the most recent version at doi:10.1101/lm.042721.116

References This article cites 21 articles, 5 of which can be accessed free at: http://learnmem.cshlp.org/content/23/8/399.full.html\#ref-list-1

Creative This article is distributed exclusively by Cold Spring Harbor Laboratory Press for the Commons License first 12 months after the full-issue publication date (see

http://learnmem.cshlp.org/site/misc/terms.xhtml). After 12 months, it is available under a Creative Commons License (Attribution-NonCommercial 4.0 International), as described at http://creativecommons.org/licenses/by-nc/4.0/.

Email Alerting Receive free email alerts when new articles cite this article - sign up in the box at the Service top right corner of the article or click here. 